\title{
MACHADO, David. Índice médio de felicidade. Porto Alegre: Dublinense, 2016. 320p.
}

\section{O mundo é um lugar complicado}

A crise econômica e o surto de desemprego que se abate sobre Portugal, ao final da primeira década do milênio, concorrem para que se agrave o sentimento de descrença acerca da identidade nacional como um valor perene. Diante dessa conjuntura, apresentam-se as razões para que Índice médio de felicidade, de David Machado, se configure como narrativa capaz de trazer ao debate o enorme vazio que separa o homem de sua própria história, a partir da inadequação da presente realidade às promessas fraudadas pela tradição que se acumulam com o passar do tempo. Desse modo, Daniel apresenta-se como personagem em conflito, tendo em vista sua falta de perspectivas a curto prazo, o que o faz recorrer a um subemprego de vendedor de aspiradores de pó como um sucedâneo à crise que se apresenta em dimensão bem mais ampla. Assim, a narrativa busca passar a limpo a inquietação que corresponde ao sentido cíclico do capital, constituindo-se na própria ideia de tudo que se precariza para logo ressurgir em sua recuperação possível. A dimensão da escrita de David Machado confirma a condição inerente ao esvaziamento das propostas de oferta de bem-estar, vitimando a classe média num somatório de adversidades.

A narrativa caminha em direção à constatação de que os índices de felicidade podem variar em países como Burkina Faso, Bulgária, Costa do Marfim e Congo, tendo em vista as diferentes realidades onde os seres humanos se inserem, e Portugal se deparar com elevados níveis de desemprego que estorvam as ambições da classe média espoliada em seu desejo, em face da crise que se instaura no âmbito do consumo. Desse modo, o desemprego que atinge Daniel amplia-se em razão da situação que coloca em xeque a economia como retrato da dependência de Portugal no contexto da Europa. A narrativa induz à condição de uma sociedade que precisa de ajuda permanente, uma vez que os descaminhos da economia abrem espaços à intolerância e à resistência do que o outro passa a representar, a partir de um mundo cada vez mais conectado, onde a solidão coletiva indica o elevado índice de pessoas cujo silêncio reverbera por meio da internet. Por sua vez, as situações para as quais o ser humano não foi preparado, nem sequer apresentado, se fazem impor em sua carga de verdades, do mesmo modo negando-lhe a condição precípua de se saber seu valor essencial.

Assim, Índice médio de felicidade exercita com extremo vigor uma escrita que se situa diante do impasse como uma ciranda que roda em torno das oscilações de um tempo de transição. Periodicamente a ordem mundial tende a sofrer abalos em sua estabilidade, atingindo de modo contundente os países cujo nível de dependência compromete suas demandas de recuperação. A isso se acrescentam as possibilidades de fruição da existência como um sistema a que se faz preciso seguir as normas, sob pena de se cair do arame e se despencar no picadeiro. Desse modo, a sequência dos atos de que se constitui a comédia cotidiana coloca suas personagens diante da dolorosa ironia que as obriga a rir para não chorar. As condições de sobrevivência diante da crise indicam o caminho do trabalho esvaziado do sentido que contraria o desejo de realização pessoal de Daniel para atirá-lo ao mercado comum do subemprego, reduzindo, com isso, a possibilidade de satisfação do que de zero a dez representa um número insignificante. Os dias se sucedem uns após os outros, implicando na capacidade de mudança que o cotidiano oferece, no sentido de sua reinvenção, de acordo com as circunstâncias possíveis.

A sequência de absurdos que acompanha a escrita de David Machado funciona como um diário destinado às gerações futuras, uma vez que aponta para o dado de realidade de situações que se afirmam como índice de instabilidade, a isso se contrapondo uma segunda possibilidade narrativa. Desse modo, verifica-se a dependência que se observa na forma como as coisas migram à revelia dos seres que se veem obrigados a mudar a rota do que previamente se estabelecera. Nesse sentido, Índice médio de felicidade atua como escrita literária que agencia a incapacidade humana diante do que se mostra na via contrária de uma ordem de desejos que se vê desviada de seu fulcro. As surpresas do inesperado assumem seu lugar, quando o desequilíbrio econômico concorre para que o agente de viagens se converta em vendedor comissionado de aspiradores de pó. Diante disso, a interlocução da narrativa com Almodóvar, o amigo que se encontra na prisão, dá conta de que Marta, 
sua mulher, não consegue conviver com sua condição de desempregado e resolve ir embora com os filhos. Diante disso, não há como retroceder ao que se mostra como realidade, em vista do desemprego que volta a bater à porta de Daniel, a partir da dívida que a perda de um aspirador de pó lhe acarreta.

O fluxo da narrativa assume o aspecto da confissão quando a Almodóvar se dirigem muitas queixas, ainda mais em vista de Daniel lhe relatar a cena de agressão física e homofobia praticada por Vasco, seu filho, num estacionamento, em companhia de outros garotos, contra Ávila, seu antigo professor de matemática, a quem, com a ajuda de Xavier, tivera que defender. Daí o mundo mostrar-se um lugar complicado, em face da violência, do desemprego, da separação e do pessimismo, o que leva Flor e Mateus, seus filhos, a alimentarem forte descrença diante de como a vida se apresenta, baixando com isso seu índice de felicidade a níveis apenas suportáveis, em face da crise que se faz presente. Em vista disso, as imagens gravadas dos garotos urinando sobre Ávila ganham o destaque de seguidas visualizações na internet, ainda que Daniel tenha jogado fora um aspirador de pó para ter espaço suficiente dentro do carro, colocado em seu lugar o amigo, para salvá-lo das agressões. No entanto, a dívida referente ao aparelho, além do acúmulo de gastos com os quais não tem como arcar, o fazem colocar em risco a posse da casa onde mora como único bem que ainda possui. A crise faz com que as relações se esgarcem ao limite, no que implica a distância que o separa de Marta e dos filhos, bem como do desejo de uma vida em comum.

A liquidação da dívida com o banco resulta na saída da casa, quando Daniel passa a dormir dentro do carro durante treze noites, a cada vez numa rua diferente. Depois de ter sido rejeitado por uma empresa de turismo religioso, segue de carro o empresário que lhe negara o emprego até eva-lo de vista. Logo em seguida, Vasco, em companhia dos garotos que agrediram Ávila, lhe passa a inquerir acerca desse fato, alegando que a situação vivida pelo antigo professor de matemática, que mora na rua, pode vir a acontecer a qualquer um. Ato contínuo, observa o alarde em torno do carro onde dorme, a pegar fogo, o que encerra um capítulo significativo de sua trajetória de fracassos. No entanto, o incêndio é contornado e Daniel segue em frente, acreditando ser isso uma ação dos amigos Vasco. Daí decorre a desolação de sua condição de desempregado a vagar pela cidade como outros tantos, a rebobinar a memória de um tempo em que a família e o trabalho se constituíam na razão de ser de uma realidade que lhe foge ao controle, como se lhe faltasse o chão onde pisa, na medida em que também se efetivam uma série de outras ausências.

A obsolescência se manifesta em razão da velha ordem, a partir do momento em que o patriarca fundador se mostra resistente a ter que trocar a logomarca da farmácia, em vista da internet e da entrega domiciliar, sendo que seus filhos, gestores formados em Marketing Empresarial, nada entendem de farmacologia. Por esse meio, segue a crise, quando os valores se renovam de modo abissal, querendo representar a derrocada do que se tornou ultrapassado, em vista das coisas que se impõem como marcas de um tempo de mudanças. Assim, a conquista de uma colocação como entregador de remédios acaba provisoriamente com a resistência do dono da farmácia, do mesmo modo que com o jejum de um ano sem emprego. Enquanto isso, prossegue a insânia dos garotos desordeiros, de cujo grupo Vasco toma parte, a partir de vídeos em que são flagrados a reproduzir situações tão miseráveis quanto a vida de Ávila, que se embriaga para em seguida prostituir-se em casas de banho. Subitamente, os algozes tornam-se vítimas de si mesmos, quando Vasco telefona a Daniel pedindo ajuda, após ingerir álcool e barbitúricos, sendo encontrado numa praia e logo após levado a um hospital de emergência. No entanto, o atendimento a Vasco, na Costa da Caparica, faz com que Daniel deixe de tomar um comboio até Viana do Castelo, para rever a mulher e os filhos.

A narrativa passa a dar sinais que se anunciam de súbito, quando Vasco constata que a interlocução de Daniel com Almodóvar, seu pai, decorre de distâncias que remetem à condição de prisioneiro do último. Por conta disso, a vida do garoto sem a assistência dos pais torna-se um vendaval de desatinos, ao passo em que Daniel lhe faz enxergar que, nesses tempos de crise, os trezentos euros que roubara de um vendedor de pastilhas e gastara em supérfluos faria falta a uma família. Por sua vez, Flor e Mateus, filhos de Daniel, manifestam-se completamente céticos diante das promessas do mundo em que vivem. A menina passa o ano quase sem tocar nos livros da escola, o que por certo compromete seu desempenho nos exames. Em seguida, resolve mudar de atitude, a pedido do pai, sendo que para ela os estudos não têm a menor importância. O garoto raspa a cabeça, no desejo de vir a tornar-se budista. Para ele, os níveis de felicidade são insuficientes, tendo em vista as promessas não cumpridas de um mundo sem alternativas de uma vida melhor. $\mathrm{O}$ casal, por sua vez, chega à conclusão de que a separação imposta pela crise representa um duro revés, na medida em que esse afastamento provisório entre Lisboa e Viana do Castelo parece eternizar-se.

No site criado por Daniel e Xavier, uma senhora paraplégica, que vive em Genebra, pede ajuda para ver o irmão que se acidentara e encontra-se à beira da morte. No entanto, se faz preciso ir ao encontro de Vasco, ameaçado pelo garoto vendedor de pastilhas, de quem roubara os trezentos euros. Por sua vez, essas pastilhas não são senão comprimidos de êxtase e pontos de LSD, 
vendidos num apartamento infecto para onde Vasco se dirige, em companhia de Daniel, no intuito de pagar a dívida. No apartamento vizinho, saindo de um banheiro nauseabundo, encontra-se Ávila, embriagado e submetido a sevícias pelos garotos libertinos amigos de Vasco. Desse episódio, Daniel conclui a respeito de não ser possível ajudar aos que não querem ajuda, uma vez que Ávila encontra-se num grau bastante abaixo do seu nível de satisfação com a vida. Não resta senão pensar na penúria do que representa dormir no escritório abandonado onde trabalhara, debaixo de sua antiga secretária. A queda em seu índice médio de felicidade corresponde nesse momento a 5,7, comum a Djibouti, Egito, Mongólia, Nigéria, Portugal e Romênia. Assim, Daniel demite-se da farmácia, esperando pelo emprego numa agência de viagens, quando uma resolução inesperada o faz ir à Suíça, ao encontro da senhora Doroteia Marques, que precisa ver seu irmão no hospital. Desse modo, deixa tudo para trás, e a partir desse dia a vida passa a ser diferente. Xavier e Daniel viajam em companhia de Flor, Mateus e Vasco, numa caminhonete guiada por Alípio, que, através do site de ajuda, se oferecera a eva-los.

A resolução de ir a Genebra e, em seguida, a Marselha, determina outra dinâmica à narrativa. $\mathrm{O}$ andamento da viagem incide na afirmação de uma ordem de pensamento que faz com que as personagens venham a emergir em situações até então imprevistas. Isso tem início com o telefonema da agência de viagens, convocando Daniel para uma última entrevista, o que se faz impraticável, em face do longo percurso a que não há como retroceder. Além disso, cada um dos passageiros da caminhonete parece mergulhado numa viagem pessoal, idealizando situações para as quais o transcurso da longa estrada inviabiliza. Por sua vez, o encontro com Doroteia Marques impõe um outro sentido à vida de Daniel, na medida em que a condição de quem tem os movimentos limitados a uma cadeira de rodas indica novas formas de ver o mundo para quem a vida se mostra como uma sucessão de transtornos. Desse modo, se faz preciso dar uma oportunidade a quem espera apenas pela morte, numa viagem que tem como objetivo colocar Doroteia Marques, presa a uma cadeira de rodas, em contato com o irmão, preso a um leito de hospital. As revelações que se apresentam no caminho de volta nada significam em termos negativos, uma vez que o sentido da vida parece ter sido reinventado, dividindo seu espaço com os demais passageiros da caminhonete.

VALDEMAR VALENTE JUNIOR Universidade Castelo Branco

Recebido: 27 de fevereiro de 2017 Aprovado: 28 de fevereiro de 2017 Contato: valdemar@castelobranco.br 